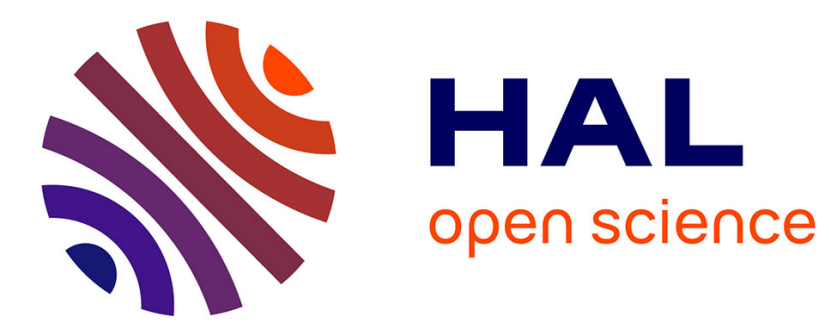

\title{
Spark plasma sintering of ductile ceramic particles: study of LiF
}

Rachel Marder, Claude Estournès, Geoffroy Chevallier, Sergey Kalabukhov, Rachman Chaim

\section{> To cite this version:}

Rachel Marder, Claude Estournès, Geoffroy Chevallier, Sergey Kalabukhov, Rachman Chaim. Spark plasma sintering of ductile ceramic particles: study of LiF. Journal of Materials Science, 2014, vol. 49 $\left(\mathrm{n}^{\circ} 15\right)$, pp. 5237-5245. 10.1007/s10853-013-7786-7 . hal-01132415

\section{HAL Id: hal-01132415 https://hal.science/hal-01132415}

Submitted on 17 Mar 2015

HAL is a multi-disciplinary open access archive for the deposit and dissemination of scientific research documents, whether they are published or not. The documents may come from teaching and research institutions in France or abroad, or from public or private research centers.
L'archive ouverte pluridisciplinaire HAL, est destinée au dépôt et à la diffusion de documents scientifiques de niveau recherche, publiés ou non, émanant des établissements d'enseignement et de recherche français ou étrangers, des laboratoires publics ou privés. 


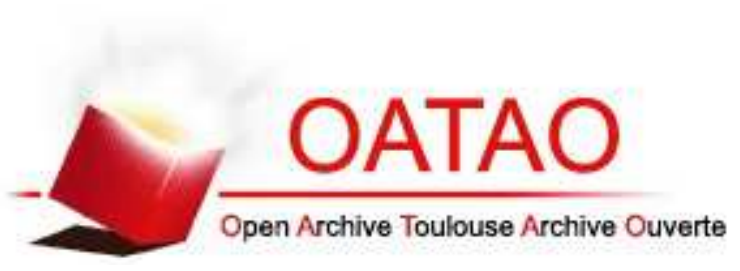

\section{Open Archive TOULOUSE Archive Ouverte (OATAO)}

OATAO is an open access repository that collects the work of Toulouse researchers and makes it freely available over the web where possible.

This is an author-deposited version published in : http://oatao.univ-toulouse.fr/ Eprints ID : 13662

To link to this article : DOI:10.1007/s10853-013-7786-7

URL : http://dx.doi.org/10.1007/s10853-013-7786-7

\section{To cite this version :}

Marder, Rachel and Estournès, Claude and Chevallier, Geoffroy and Kalabukhov, Sergey and Chaim, Rachman Spark plasma sintering of ductile ceramic particles: study of LiF. (2014) Journal of Materials Science, vol. 49 ( $\left.\mathrm{n}^{\circ} 15\right)$. pp. 5237-5245. ISSN 0022-2461

Any correspondance concerning this service should be sent to the repository administrator: staff-oatao@listes-diff.inp-toulouse.fr 


\title{
Spark plasma sintering of ductile ceramic particles: study of LiF
}

\author{
R. Marder · C. Estournès · G. Chevallier · \\ S. Kalabukhov $\cdot$ R. Chaim
}

\begin{abstract}
Densification of cuboidal micrometer-sized lithium fluoride particles as ductile ceramic by spark plasma sintering (SPS) was investigated. Specimens were fabricated at different pressures and temperature conditions, ranging from 2 to $100 \mathrm{MPa}$ at $500{ }^{\circ} \mathrm{C}$ and from 200 to $700{ }^{\circ} \mathrm{C}$ under $100 \mathrm{MPa}$ of applied pressure, respectively. Dense specimens of $99 \%$ relative density were fabricated by heating to $500{ }^{\circ} \mathrm{C}$ under constant pressure of $100 \mathrm{MPa}$. The densification showed first compaction by particle rearrangement, followed by plastic deformation via dislocation glide. Hot-pressing models were used to describe the densification by considering the temperature dependences of the yield stress, the strain hardening behavior and coefficients, and the pore size and shape dependences on the applied stress. A good agreement was found between the experimental and the theoretical densification curves. At low pressure of $2 \mathrm{MPa}$, the densification occurs by particle sliding, assisted by viscous flow at their surfaces, and local plastic deformation at the particle contacts, due to the intensified local stress. Finally, the micrometer-sized structural features and the contiguity achieved by plastic
\end{abstract}

R. Marder $(\varangle) \cdot$ R. Chaim

Department of Materials Science and Engineering,

Technion - Israel Institute of Technology, 32000 Haifa, Israel

e-mail: rachelma@tx.technion.ac.il; rachelma@technion.ac.il

C. Estournès · G. Chevallier

Institut Carnot Cirimat, Université de Toulouse, UPS, INP, 118, route de Narbonne, 31062 Toulouse Cedex 9, France

C. Estournès - G. Chevallier

Institut Carnot Cirimat, CNRS, 31062 Toulouse, France

S. Kalabukhov

Department of Materials Engineering, Ben-Gurion University of the Negev, 84105 Beer-Sheva, Israel deformation at the start of spark plasma sintering (SPS) nullify any field effects in this model system at higher pressures; good agreement was obtained with expected conventional hot pressing.

\section{Introduction}

Spark plasma sintering (SPS) is a novel sintering technique currently used for rapid and full densification of ceramic powder compacts within a few minutes. Although the exact details of the densification mechanisms are yet under study, the enhanced densification kinetics are related to the fieldaffected processes, either by increasing the mobility of the defects associated with diffusion, or by providing additional driving force for diffusion [1-3]. Significant differences of the electric field effects may be expected for ductile versus brittle ceramics, with respect to the early stages of densification $[4,5]$. Ductile ceramic particles subjected to applied pressure may undergo small rearrangement, but severe plastic deformation during the heating. In comparison, significant rearrangement and negligible plastic deformation are expected for hard ceramic particles. The applied electric field may contribute to plastic deformation at high temperatures by lowering the flow stress [6]. However, the gained contiguity in the ductile particle network may nullify the possible plasma and other field effects associated with the particle surfaces. Plastic deformation of LiF has been thoroughly investigated [7-10]. In the present article, densification of micrometer-sized $\mathrm{LiF}$ particles was studied as a model system for ductile ceramic particles subjected to SPS at different conditions. 


\section{Experimental}

High purity lithium fluoride (LiF, $99.995 \%$, SigmaAldrich) powder was used. The powders were sintered using either the SPS units (Dr. Sinter, SPS 2080 at the plateforme Nationale CNRS de Frittage Flash PNF2/CNRS in Toulouse or FCT System GmbH HP D 5/1, in BGU). The powders were poured into the graphite die with $8-\mathrm{mm}$ inner diameter. The green compact was isolated from the die surfaces using graphite foils (Grafoil).

Two SPS modes were used to fabricate the dense specimens. In the first mode (mode I), four specimens were fabricated (Dr. Sinter unit) using different pressures (2, 32, 64 , and $100 \mathrm{MPa}$ ). The powder was heated from room temperature to $500{ }^{\circ} \mathrm{C}$ at the rate of $100{ }^{\circ} \mathrm{C} \mathrm{min}{ }^{-1}$, under the applied pressure; when reaching this temperature, the process was stopped by releasing the pressure and rapid cooling of the system. Hence, no isothermal holding time was used.

In the second mode (mode II), four specimens were fabricated (FCT unit) using different temperatures (200, 300,500 , and $\left.700{ }^{\circ} \mathrm{C}\right)$. The heating rate was $65^{\circ} \mathrm{C} \mathrm{min}^{-1}$, and a pressure of $100 \mathrm{MPa}$ was used. The pressure was increased gradually with the temperature increase until the $100 \mathrm{MPa}$ was reached at the SPS temperature. When reaching the SPS temperature, the specimens held at this temperature for 5-min duration. In both modes, all the SPS process parameters were recorded versus time. The temporary relative density of the specimens was calculated according to the displacement of the punch and the specimen height, as described elsewhere in detail [11].

The density of the final specimens was measured both by weighing and using the Archimedes method with distilled water medium; the techniques were used for the specimens with relative densities less than and greater than 0.9 , respectively. The microstructures of the powder and the specimens were characterized using scanning electron microscopy (SEM, FEI E-SEM Quanta-200) operated at $20 \mathrm{kV}$. The grain size was determined from the polished and chemically etched surfaces; at least, 200 grains were counted for each specimen. X-ray diffraction (XRD) measurements were used for structure and residual stress analyses, using X-ray diffractometer (Rigaku SmartLab) equipped with monochromated $\mathrm{Cu} \mathrm{K} \alpha$ radiation, operated at $40 \mathrm{kV}$ and $40 \mathrm{~mA}$. Scanning speed of $0.02^{\circ} \mathrm{s}^{-1}$ was used.

\section{Results}

The LiF powder particles exhibited cuboidal morphology with an average edge size $6.5 \pm 2.6 \mu \mathrm{m}$ (Fig. 1a). XRD spectrum of the as-received powder (Fig. 1b) revealed a
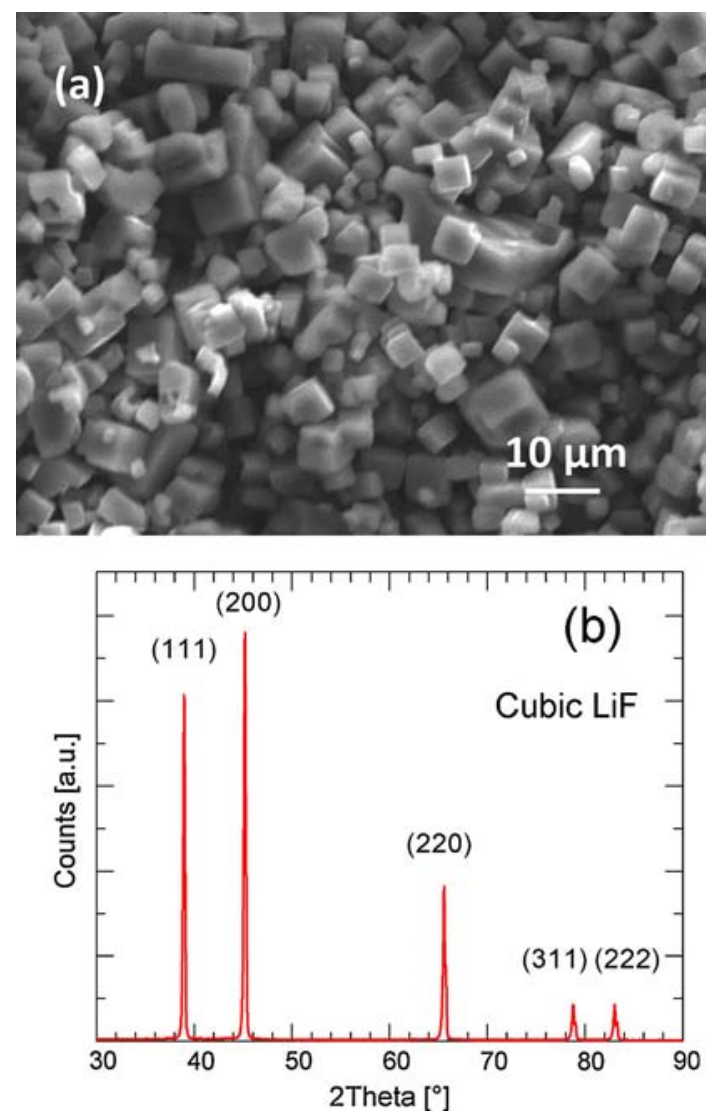

Fig. 1 a SEM image from the as-received LiF powder with cuboidal morphology. b XRD spectrum is in agreement with the cubic crystal symmetry

cubic phase in agreement with the JCPDS card \# 04-0857 for LiF. The density change versus temperature is shown by solid lines in Fig. 2a for the different specimens fabricated by mode I. The pressure application at the SPS start led to an instantaneous compaction of the powder. With an increase in the temperature, the densification further continued by plastic deformation (as will be explained below) for the specimens sintered at 32,64, and $100 \mathrm{MPa}$. The holding pressure of $2 \mathrm{MPa}$ was too low for further increase in density up to $\sim 160{ }^{\circ} \mathrm{C}$; only at $\sim 160{ }^{\circ} \mathrm{C}\left(0.39 \cdot T_{\mathrm{m}}-T_{\mathrm{m}}\right.$ is the melting point of $\mathrm{LiF} \sim 850{ }^{\circ} \mathrm{C}$ ), the density increased again under this lowest pressure. The linear shrinkage rates for the mode I specimens, compacted between 2 and $100 \mathrm{MPa}$ at temperatures above $200{ }^{\circ} \mathrm{C}$ up to $90 \%$ density, varied between $10^{-4}$ and $10^{-3} \mathrm{~s}^{-1}$, regardless of the pressure level.

The green density after compaction, but before the heating, versus the applied pressure, is shown in Fig. $2 b$. Such compaction plot in the semilogarithmic scale may exhibit three linear regions which refer to different densification stages and processes in the green compact [12]. The present results can be fitted into two linear lines (Fig. 2b) indicating that similar densification process 

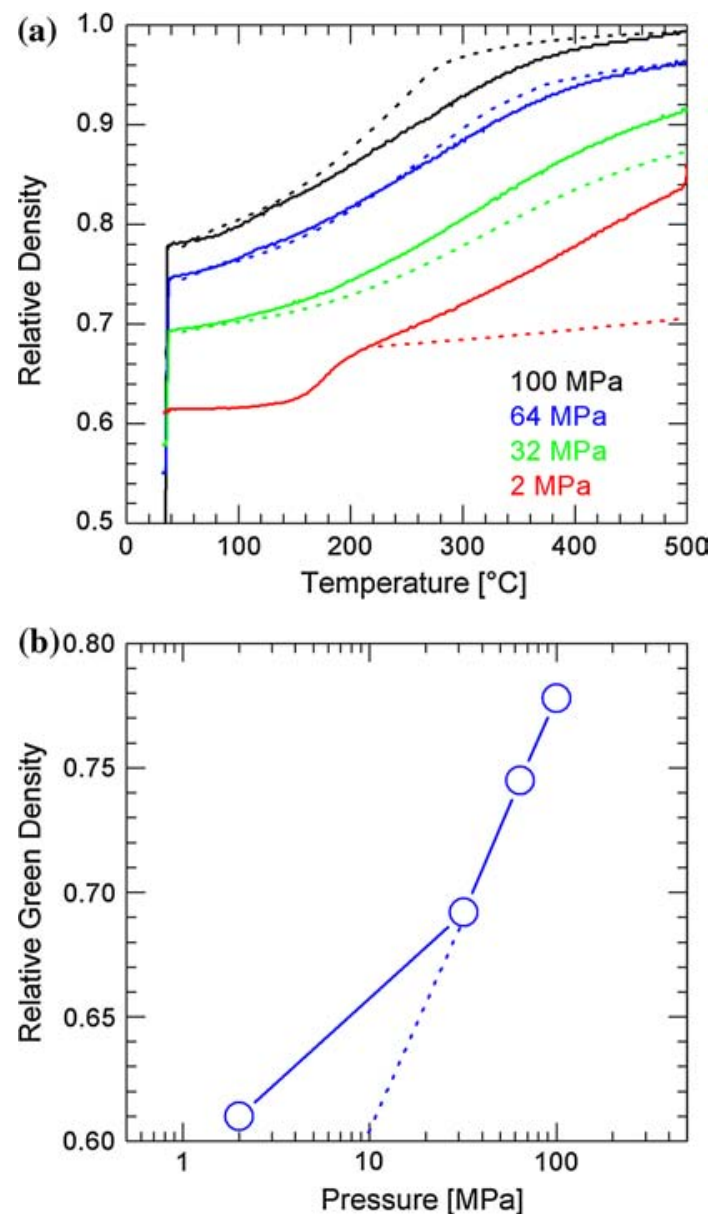

Fig. 2 a Experimental (solid lines) and calculated (dashed lines) density versus SPS temperature for mode I specimens heated to $500{ }^{\circ} \mathrm{C}$ under different applied pressures. b Green density versus applied pressure; the dashed line shows the extrapolation of the line at higher pressures to the lower pressures. It indicates that the actual densification mechanism at the lowest pressure of $2 \mathrm{MPa}$ differs from that at higher pressures

occurs at the higher pressures, and it differs from that at $2 \mathrm{MPa}$. Extrapolation of the lines at higher pressures to the lower densities (i.e. dashed line in Fig. $2 b$ at 0.61 ) shows that a pressure of $\sim 10 \mathrm{MPa}$ is needed for the activation of the same densification process at the lower densities; this pressure is higher by one order of magnitude than the actual applied pressure ( $2 \mathrm{MPa})$. The fact that a relative density of 0.61 was reached already at $2 \mathrm{MPa}$, points to a different densification mechanisms (i.e., particle rearrangement and sliding), active at lower densities versus plastic deformation at higher pressures, as will be explained in the discussion.

The density of the specimens sintered by mode II versus process time and temperature are shown in Fig. 3. The different initial densification rates (slopes of the curves at their initial linear portion) for the specimens sintered to different temperatures are due to the different pressure
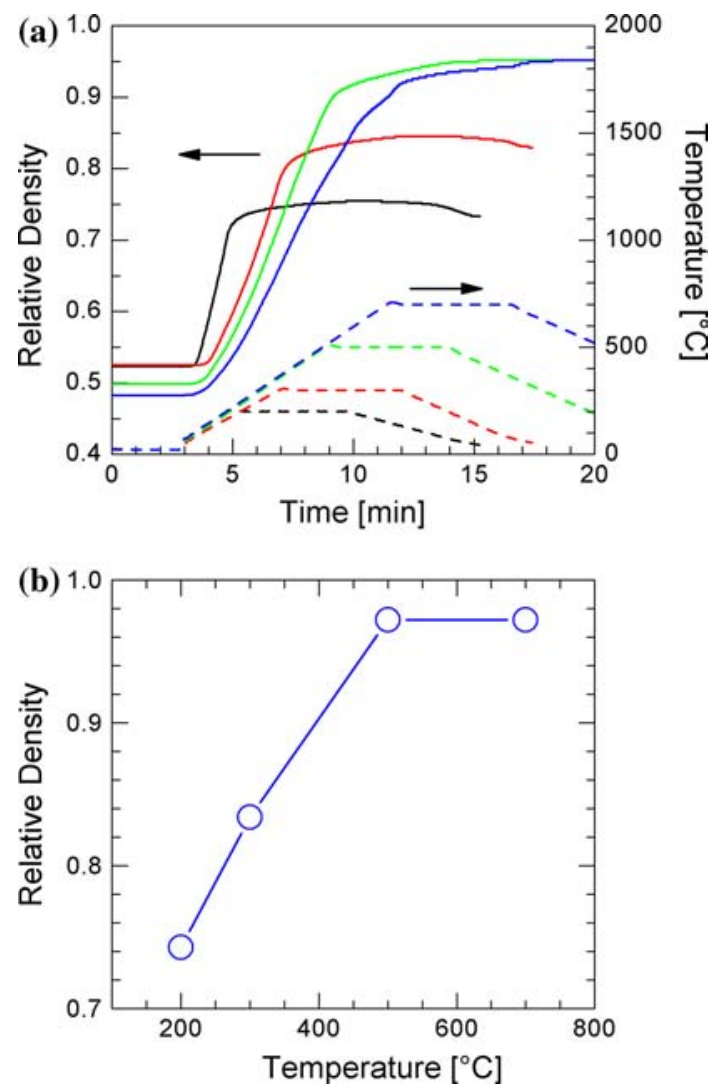

Fig. 3 a Relative density (solid lines) and corresponding process temperature (dashed lines) of mode II specimens sintered at $100 \mathrm{MPa}$ for $5 \mathrm{~min}$ versus process time. b Final density versus temperature

increase rates; the $100 \mathrm{MPa}$ pressure was attained at different process durations. The specimen sintered at the lowest temperature of $200{ }^{\circ} \mathrm{C}$ experienced the shortest duration, hence the highest pressure increase rate. The densification always started immediately after pressure application (after 3-min system stabilization time). Once the maximum pressure and temperature were reached, further small increase in density was obtained at constant pressure with time during the SPS isotherms (Fig. 3a). SPS above $500{ }^{\circ} \mathrm{C}$ resulted in very dense specimens (above $97 \%$ ) (Fig. 3b). The specimens sintered at 500 and $700{ }^{\circ} \mathrm{C}$ reached almost the same final density after $18 \mathrm{~min}$ (total SPS process time). Further densification to $100 \%$ density may necessitate higher pressures or temperature as is evidenced from the observed asymptotic density behavior with time.

The grain size grew with the increase in the applied pressure (mode I) and the temperature (mode II), as shown in Fig. 4. Grain growth was quite modest up to $300{ }^{\circ} \mathrm{C}$, while significant grain growth was observed at 500 and $700{ }^{\circ} \mathrm{C}$. The sintered microstructure, grain and pore size, and morphology change, with the increase in the applied pressure (mode I) and temperature (mode II), 
are shown in the SEM images in Figs. 5 and 6. The cuboidal morphology of the LiF particles was retained in the mode I specimens sintered under $2 \mathrm{MPa}$ (Fig. 5a) and $32 \mathrm{MPa}$ (Fig. 5c), while the grains at higher SPS pressures exhibited prismatic polyhedral morphology (Fig. 5d). Formations of steps at the particle surfaces, associated with shear traces, provided evidence for the plastic deformation by shear (arrowed in Fig. 5b). These steps can be distinguished from the steps that smaller crystals form, when sintered to the surfaces of larger crystals (labeled by "A," "B," and "C" in Fig. 5b)

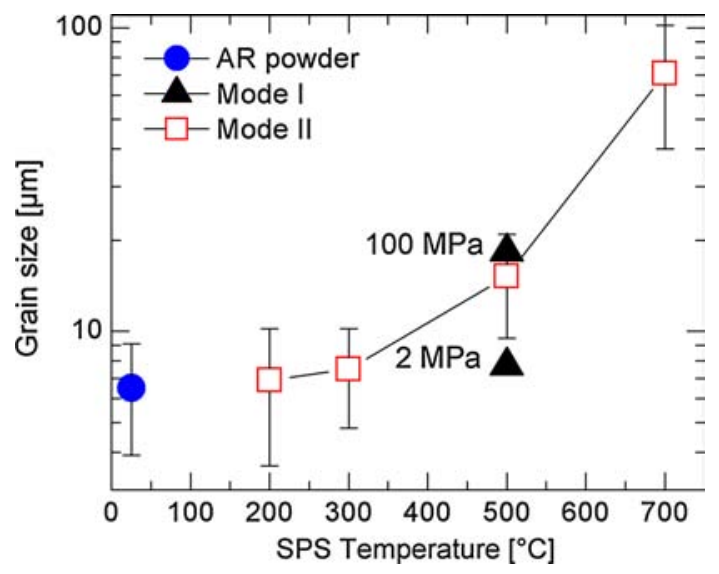

Fig. 4 Grain size versus SPS temperature for the LiF specimens sintered at different modes exposed to high SPS temperatures. The cubical morphology in mode II-sintered specimens was retained below $300{ }^{\circ} \mathrm{C}$. Above this SPS temperature, prismatic polyhedral grains were observed (Fig. 6c). The sharp $90^{\circ}$ pores at low SPS pressures and temperatures converted to blunt $120^{\circ}$ pores with the density increase at higher SPS pressures and temperatures.

XRD spectra of the mode II specimens sintered below $300{ }^{\circ} \mathrm{C}$ were almost identical to that of the as-received powder (Fig. 7a). However, the specimens sintered at 500 and $700{ }^{\circ} \mathrm{C}$ exhibited significant changes in the peak relative intensities (Fig. 7b); a preferred orientation of the (200) peak was clearly observed. In addition, a few narrowings in the peak width were noted at these temperatures. The XRD measurements were taken parallel to the specimen surfaces, which are perpendicular to the uniaxial SPS pressure direction. Due to the micrometer-sized grains, the peak width changes at full width at half maximum (FWHM) were assumed to originate from the residual strain only. The residual strain values determined from the (200) $\mathrm{K}_{\alpha 1}$ FWHM line broadening for the specimens sintered at 500 and $700{ }^{\circ} \mathrm{C}$ only were of the order of $4.6 \times 10^{-4}$ (comparable with residual stresses of $\sim 30 \mathrm{MPa}$ ). The shifts of the (220) peak angles were also analyzed. However, these shifts were of the same order of the standard deviation of the angle value measurements (i.e. $0.8 \%$ of the angle value); hence, no significant peak shifts exist.
Fig. 5 SEM images of mode I specimens sintered to $500{ }^{\circ} \mathrm{C}$ and at different pressures: a, b $2 \mathrm{MPa}$, c $32 \mathrm{MPa}$, and d $100 \mathrm{MPa}$. Steps at the surfaces are formed by plastic shear deformation (arrowed in b) and can be distinguished from steps formed by sintering of small particles to surfaces of larger particles $(A, B$, and $C$ in b)
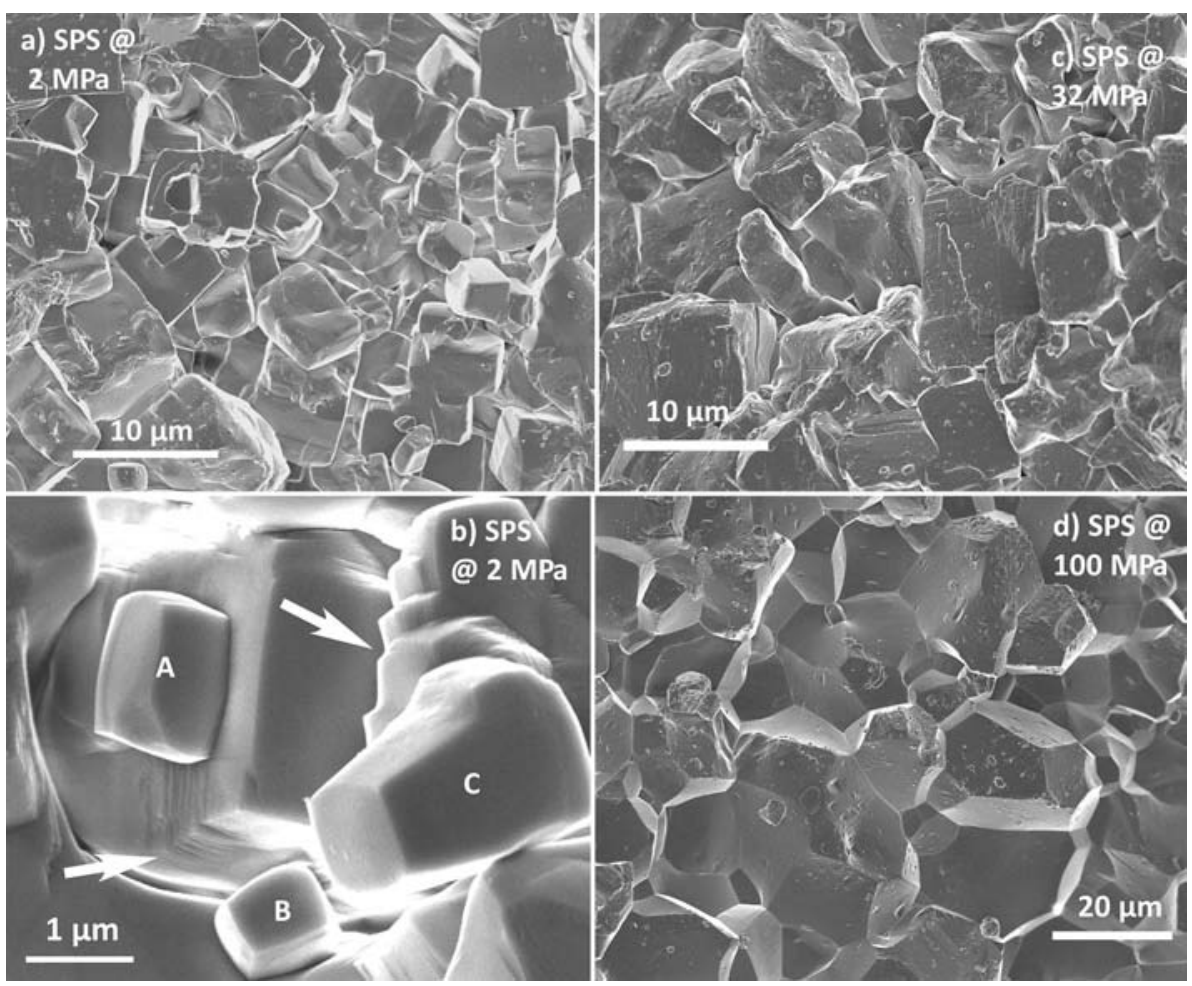


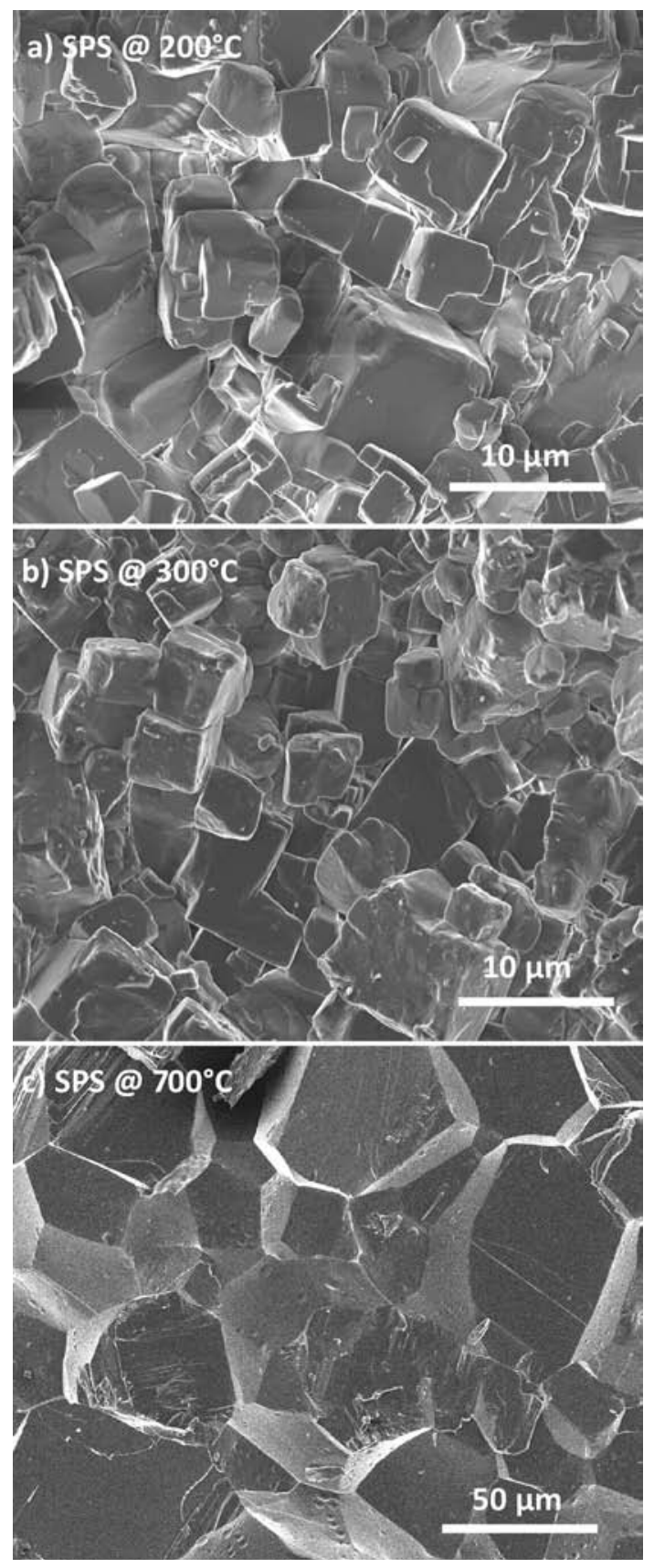

Fig. 6 SEM images of mode II specimens sintered at $100 \mathrm{MPa}$ and different temperatures: a $200{ }^{\circ} \mathrm{C}$, b $300{ }^{\circ} \mathrm{C}$, and c $700{ }^{\circ} \mathrm{C}$

\section{Discussion}

In mode I specimens, constant pressure was applied to the specimens at room temperature, followed by temperature increase at constant heating rate to $500{ }^{\circ} \mathrm{C}$. This was performed using different pressures $(2,32,64$, and $100 \mathrm{MPa})$. This experiment simulates conditions of creep at varying temperatures. Steady state creep holds at temperatures higher than $0.4 \cdot T_{\mathrm{m}}$, which is $\sim 175{ }^{\circ} \mathrm{C}$ for LiF. Creep in $\mathrm{LiF}$ is associated with dislocation motion rather than with
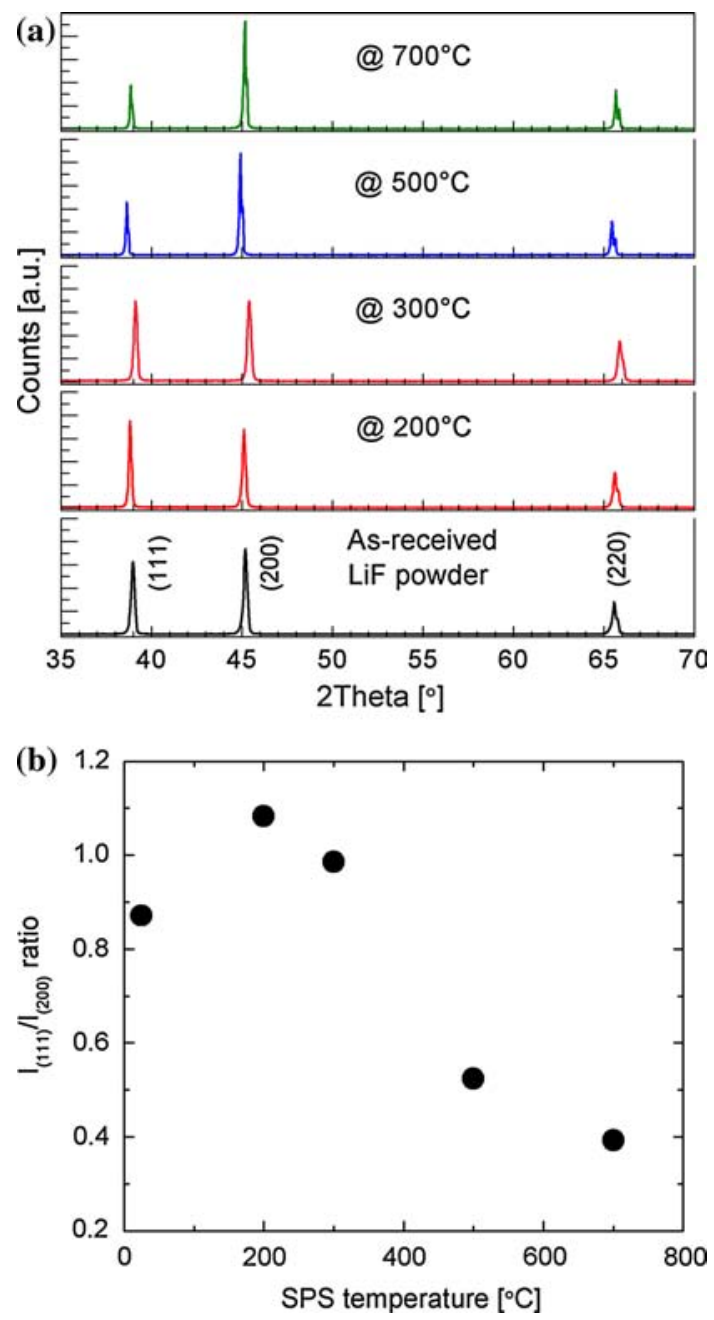

Fig. 7 a XRD spectra of the as-received powder and mode II specimens sintered at $100 \mathrm{MPa}$ for $5 \mathrm{~min}$ at different temperatures. b Ratio of the (111) to (200) peak intensities. Decrease in the peaks intensity ratio indicates on formation of preferred orientation at 500 and $700{ }^{\circ} \mathrm{C}$ SPS treatments

vacancy diffusion [13]. This is in accordance with the deformation mechanism maps for $\mathrm{LiF}$ crystal size of interest, i.e., $10 \mu \mathrm{m}$ and the current applied pressure and temperatures [10]. Therefore, the significant densification during the heating up to $500{ }^{\circ} \mathrm{C}$ must be accomplished by plastic flow via dislocation movements, as will be treated below.

The overall density and grain size results point toward densification by particle rearrangement, followed by plastic deformation and grain growth. All processes were enhanced with increases both in pressure and temperature. The green density of the compacts ranged between 48 and $61 \%$ under the holding pressure of $2 \mathrm{MPa}$ (Figs. 2, 3). Therefore, the early densification can be related to particle rearrangement aided by local plastic deformation of the $\mathrm{LiF}$ particles. Once the yield stress is reached at the contact 
points, the single crystal particles begin to deform plastically at these loci, to allow further densification by rearrangement. This may continue until random close-packed condition is reached ( 0.64 for unisize spherical and 0.72 for unisize cuboidal particles [14]). At higher densities, matter redistribution from the contact points into the empty voids, by plastic deformation, will constitute significant contribution to the overall densification. $\mathrm{LiF}$ is a relatively soft ceramic and is known to undergo plastic deformation at moderate pressures (2-27 MPa) in the temperature range of 25-300 ${ }^{\circ} \mathrm{C}[7-10,15-19]$. The maximum shear stress at the yield and the flow stress versus temperature were reported for pure and impure $\mathrm{LiF}$ single crystals. The critical resolved shear stresses (CRSS), during compression (bending) of $\mathrm{LiF}$ at room temperature and strain rates of $10^{-4}$ and $10^{-3} \mathrm{~s}^{-1}$ (typical for SPS), vary between 8 and 16.5 $\mathrm{MPa}$ for $\langle 001\rangle$ and $\langle 011\rangle$ orientations, respectively, for the $\{110\}\langle 110\rangle$-type slip systems [19]. Averaging the stresses over these directions with respect to their abundance (multiplicity factors of 3 and 6), the yield shear stress of $13.6 \mathrm{MPa}$ may be expected for the LiF compact. This is very close to the maximum shear stress at yield of "pure" LiF single crystals of $\sim 11 \mathrm{MPa}$ derived by compression at room temperature $[16,18]$. The minimal externally applied pressure needed for plastic deformation at the early stage of densification $(\rho \ll 0.9)$ can be calculated by [20]

$P_{\text {min }}=\frac{3 \sigma_{\text {flow }}}{4 \pi} \cdot\left(\rho-\rho_{0}\right) \cdot\left[160\left(\rho-\rho_{0}\right)+16\right]$

where $\sigma_{\text {flow }}$ is the flow stress, and $\rho_{0}$ and $\rho$ are the relative green and temporary densities, respectively. The flow stress varies with temperature, a fact that should be taken into account, while using Eq. (1). For uniaxial loading, the flow stress may equal from $\sqrt{ } 3$ to 2 times the critical shear stress for yield, according to von Mises and Tresca yield criteria, respectively [21]. The model used to develop Eq. (1) is based on the idea, that matter is equally redistributed from the contact area to the remaining free surfaces of the particles. This redistribution results in a uniform increase of the particle radius and a decrease in center-to-center distance of the particles. The (100) surfaces of the LiF single crystal particles (very stable with the lowest surface energy) constitute all the external surfaces of the cuboidal crystals. Therefore, matter is considered to be equally redistributed from the bulk of the crystal to all these surfaces which form the pore surface; this is similar to that of the isotropic surfaces of the spherical particles in the used model, and should result in an even increase of the cube edge "length/dimension," similar to an increase in the radius of the spherical particles.

Using Eq. (1) with a relative-green density of 0.55 for the present $\mathrm{LiF}$ powder, and a temporary density of 0.61 (up to $160^{\circ} \mathrm{C}$ ) which corresponds to the density of the specimen at the holding pressure of $2 \mathrm{MPa}$, the external stress needed for plastic flow can be estimated. The values used for the flow stress were between 19 and $22 \mathrm{MPa}$, estimated using the maximum shear stress for yield of "pure" LiF single crystals at room temperature, which is $11 \mathrm{MPa}$ [18]. According to Eq. (1), an external pressure between 7 and $8 \mathrm{MPa}$ is needed to carry the plastic flow for densification. This may explain the lack of plastic deformation up to $\sim 160{ }^{\circ} \mathrm{C}$ when a holding pressure of $2 \mathrm{MPa}$ was used. However, above $\sim 160{ }^{\circ} \mathrm{C}$, the flow stress decreases to $5.5 \mathrm{MPa}$, and the corresponding applied pressure needed for yield is $2.0 \mathrm{MPa}$, which is identical to the holding pressure (Fig. 2). Moreover, higher SPS pressures of 32, 64, and $100 \mathrm{MPa}$ used in this study, will always lead to plastic flow in LiF according to Eq. (1). It should be noted that LiF crystals subjected to high plastic strains and high temperatures (i.e., between 330 and $800{ }^{\circ} \mathrm{C}$ ) in the strain rate range of $10^{-3}-10^{-2} \mathrm{~s}^{-1}$, exhibited superlocalization of the plastic deformation in compression [17]. The deformation mechanism in such conditions involves dislocation glide. A similar behavior may be expected for the particles in the present powder compacts subjected to the high strains and temperatures.

Densification by plastic flow is instantaneous when sufficient pressure is applied. In this respect, the final density attainable by plastic deformation through dislocation glide can be estimated at the second stage $(\rho<0.9)$ and the final stage $(\rho>0.9)$ sintering by [22]

$\rho_{f}=\left[\frac{\left(1-\rho_{0}\right) \cdot P_{\mathrm{appl}}}{1.3 \cdot \sigma_{y}}+\rho_{0}^{3}\right]^{\frac{1}{3}} ; \quad \rho<0.9$

$\rho_{f}=1-\exp \left(-\frac{3}{2} \frac{P_{\mathrm{appl}}}{\sigma_{y}}\right) ; \quad>0.9$

where $P_{\text {appl }}$ is the applied pressure, and $\sigma_{y}$ is the yield stress.

In order to use the above equations for evaluation of the expected density in the compacts versus the SPS temperature and pressure, some physical and microstructural aspects should also be considered. These include the temperature dependence of the yield stress, the strain hardening behavior and coefficients, and the pore size and shape dependences of the stress intensification factor. Each of these parameters will be discussed accordingly.

The yield stress of LiF single crystals sharply decreases with the temperature increase, as expected for ionic crystals. The temperature dependence of the yield stress in $\mathrm{LiF}$ single crystals was investigated from liquid nitrogen temperature up to high elevated temperatures $[8,9,15-18]$. Since the yield stress in LiF strongly depends on the crystal purity, on the applied strain rate, as well as on the crystal orientation and the active glide system, a wide range of 
stress values at room temperature have been reported. Nevertheless, we assume that at the early stage of densification, i.e., up to $74 \%$ density, the particle rearrangement is followed by plastic yield of the cuboidal LiF single crystal particles via the easiest slip system, i.e., $\{110\}$ $\langle 110\rangle$-type with $\langle 001\rangle$ compression axis [19]. This is justified since the elastic constraint around the particles is negligible. However, once plastically deformed necks form a "closed-packed" structure, further plastic deformation is expected to follow that of a polycrystalline material with elastic constrain around each grain. In $\mathrm{MgO}$, the flow stress of a polycrystal in compression was assumed to be determined by the hard slip system [10] which is in LiF of $\{100\}$ $\langle 110\rangle$-type [15]. However, stress-strain curves in bending of LiF crystals at different orientations revealed an about three times higher yield point for crystals with near, but not perfect $\langle 111\rangle$ orientations, than for the hard $\langle 110\rangle$ orientation [19]. Therefore, the temperature dependence of the yield stress used in our calculations was that of the CRSS of the $\{100\}\langle 110\rangle$ hard system [15].

The applied pressure leads, in addition to the particle rearrangement, also to plastic deformation and hardening of the powder particles. The classic treatment of the strain hardening is by:

$\sigma_{p}=K \varepsilon_{p}^{n}$

where $\sigma_{p}$ and $\varepsilon_{p}$ are the true plastic stress and strain for dense material and $K$ and $n$ are the strength coefficient and the strain hardening exponent of the material, respectively. LiF single crystals undergo yield followed by easy glide, as expected for cubic single crystals [7, 23]. On the other hand, LiF exhibits irregular strain hardening after easy glide; where the plastic stress increment is linearly proportional to the dislocation density, hence to the plastic strain [7]. This linear hardening originates from the dislocation capability in $\mathrm{LiF}$ to move long distances without dislocation tangling. Strain hardening in dense polycrystalline LiF was also observed to be linear with the plastic strain, albeit the strength coefficient $K$ of the strain hardening significantly increased [19]. Consequently, linear strain hardening with lower $K$ is expected for lower relative densities of the powder compact.

The relative density of the powder compact increases continuously, thus the effective stress at the particle contacts decreases continuously with the increase in density. The particle contacts play a significant role during the early densification stages, however, at densities between random close-packed and ordered close-packed conditions. At the very early stages (densities between 0.64 and 0.74 for unisize spherical particles), stress concentration enhances local yield and may promote densification by particle rearrangement. When random close packing is reached, the stress concentration at the contact points, which depends on the applied external pressure and the yield point of the material, starts to be significant for strain hardening. Therefore, slip/slide of the particles continues at lower densities by local plastic yield, while at higher densities, extensive plastic deformation occurs within the particles.

Moreover, pores act as stress concentrators and may cause local yield and strain hardening, depending on the pore size, shape, and volume fraction. The strain hardening behavior of the porous compact during deformation has to consider the effects related to the pore morphology and size change, as described for the deformation of porous metallic alloys [24]. The plastic stress in the porous compact can be described by Eq. (4), with an additional parameter accounting for the pore effect:

$\sigma_{p}=\phi K \varepsilon_{p}^{n}$

where $\phi$ is the stress intensification factor, accounting for the notch strengthening effect due to the pores, and it varies between 2.8 for sharp pores and 1.0 for blunt pore morphology. The strain hardening in porous compacts at a given temperature thus depends on three parameters: the strain hardening characteristics of the material ( $n$ and $K$ ), the relative density of the compact, and the pore morphology.

The final density attainable by plastic deformation was calculated using Eqs. (2) and (3), and taking into account the increase in the yield stress by linear strain hardening at higher pressures, and the decrease in the yield stress due to the temperature increase. For the higher pressures of 32, 64 , and $100 \mathrm{MPa}$, the effective yield stress was calculated using Eq. (5) with strength coefficients of $K=35 \mathrm{MPa}$ [25] and $K=68 \mathrm{MPa}$ [23], for the early $(\rho<0.9)$ and the final $(\rho>0.9)$ stages of densification, respectively. The used strain hardening exponent was $n=1.0$, due to the linear strain hardening behavior of LiF. $\phi$ was chosen to decrease from 2.8 for the loose compact $(\rho=0.6)$ to 1.0 for the dense compact ( $\rho=0.9)$, using a reciprocal function. For the densification at low pressure of $2 \mathrm{MPa}$, the effective yield stress without strain hardening was used. The calculated densities versus the SPS temperatures at different pressures are shown as dotted lines in Fig. 2a, and are generally in good agreement with the experimental results (solid lines in Fig. 2a). As is evident from Fig. 2a, densification during the heating at 2-MPa holding pressure starts only above $160{ }^{\circ} \mathrm{C}$. Using the Stokes-Einstein equation, the surface viscosity of the LiF particles may be estimated versus the deformation temperature. The viscosity typically used to assign the strain point in glasses, as unset temperature for viscous plastic deformation, is $3 \times 10^{13}$ Pa.s [26]. Using the conservative lattice diffusion coefficient of fluorine, as the slowest diffusing specie in $\mathrm{LiF}$ [27], with ionic radius $0.119 \mathrm{~nm}$, this unset viscosity is reached at $180{ }^{\circ} \mathrm{C}$. Therefore, densification at $2 \mathrm{MPa}$ may 
proceed by particle sliding assisted by viscous flow at their surfaces, and local plastic deformation at the particle contacts due to the intensified local stress. This may be in agreement with the linear densification up to $500^{\circ} \mathrm{C}$ at $2 \mathrm{MPa}$, which is in contrast to the densification curves at higher pressures, where the densification rate continuously decreases above $\sim 300{ }^{\circ} \mathrm{C}$.

Pressureless sintering of cuboidal $\mathrm{LiF}$ particles with 2-3 $\mu \mathrm{m}$ particle size, between 600 and $700{ }^{\circ} \mathrm{C}$, showed decrease in the densification rate when the pore continuity was broken up at relative density 0.8 [28]. This was related to a buildup of gas pressure in the isolated pores and counteracting the sintering stress. However, under the applied pressure of $100 \mathrm{MPa}$ in our study, and low surface energy of $0.340 \mathrm{~J} \mathrm{~m}^{-2}$ for $\{100\}$-type planes [29], the smallest pore diameter to halt sintering is of the order of $0.68 \mu \mathrm{m}$, smaller than the observed closed pores. This may indicate that shrinkage stresses can be accommodated mainly by interparticle shear which becomes harder with pore elimination during the densification.

In mode II specimens, the pressure was linearly increased during the heating to reach $100 \mathrm{MPa}$ at the SPS temperature. The SPS isobar-isotherms were kept for 5-min duration. This was performed for different SPS temperatures. Therefore, this experiment simulates conditions of densification by particle rearrangement and plastic deformation, depending on the stress level, followed by creep at constant temperature. As was noted above, creep in $\mathrm{LiF}$ is associated with dislocation motion, hence all densification curves at $100 \mathrm{MPa}$ can be treated in terms of plastic deformation by dislocation glide. In this respect, the linear portions of the densification curves (Fig. 3a) comprise the main contribution to densification, and may be treated using Eq. (1) as it was used for mode I specimens, the stress intensification factor, the temperature dependence of the yield stress, and the linear strain hardening.

Creep may play an important role during densification of ductile ceramic compacts, especially at high temperatures. However, contribution of creep to densification during the SPS is often negligible due to the short processing durations involved. The experimental shrinkage rates at the end of the linear portions of the densification curves range between $2.06 \times 10^{-3}$ and $7.65 \times 10^{-3} \mathrm{~s}^{-1}$ at the temperature range of $200-700{ }^{\circ} \mathrm{C}$ (Fig. 3a), respectively. Following the deformation mechanism map for LiF crystals with $10-\mu \mathrm{m}$ crystal size, creep at $100 \mathrm{MPa}$ isobars should take place by dislocation glide [10]. The dislocation density is the origin of the residual stress observed in both the as-received and the compacts densified below $300{ }^{\circ} \mathrm{C}$. The lattice self-diffusion coefficients of $\mathrm{F}$ and $\mathrm{Li}$ ions are strongly temperature dependent $[30,31]$. While the typical diffusion distance at $700{ }^{\circ} \mathrm{C}$ is between 3 and $5 \mu \mathrm{m}$, it decreases from 3 to $5 \mathrm{~nm}$ at $200{ }^{\circ} \mathrm{C}$. This may explain the relaxation of the residual stresses observed only at SPS temperatures above $500{ }^{\circ} \mathrm{C}$.

Finally, the micrometer-sized structural features and the contiguity achieved by plastic deformation at the SPS start seems to nullify any field effects related to the free surfaces in this model system at higher pressures. At high temperatures, the electric field may affect plastic deformation by lowering the flow stress, as reported for different oxides at high homologous temperatures $\left(>0.65 \cdot T_{\mathrm{m}}\right)$; e.g., during tensile experiments of dense $\mathrm{MgO}$ at $1500{ }^{\circ} \mathrm{C}$ the flow stress decreased from $17 \mathrm{MPa}$ to about $7 \mathrm{MPa}$, when applying a dc electric field of $220 \mathrm{~V} \mathrm{~cm}^{-1}$ [6]. This decrease in flow stress was related to the enhanced diffusion of vacancies in the space-charge cloud, near the grain boundaries, due to the reduction in the electrochemical potential of the vacancies. However, in the present study plastic deformation occurs by shear already at low temperatures where diffusional processes are unlikely to contribute to the flow stress. Therefore, the effect of the applied field on the densification seems to be minimal. Moreover, a good agreement was obtained with conventional hot-pressing kinetics with no electric field effects.

\section{Conclusions}

Densification of cuboidal micrometer-sized LiF particles as ductile ceramic by SPS was investigated at different pressures and temperature conditions. Densification occurs by particle rearrangement, followed by plastic deformation via dislocation glide. The experimental densification curves can be described using well-developed hot-pressing models, while taking into account the strain hardening and temperature dependence of the yield stress, and the stress intensification at the particle contacts and the pores. The enhanced densification kinetics at low pressure of $2 \mathrm{MPa}$ were related to particle rearrangement and sliding, assisted by viscous flow at the particle surfaces. The compact contiguity formed at the early stages of the SPS process due to plastic deformation, cancel possible field effects, such as spark discharge between particles at higher pressures.

Acknowledgements The authors thank Prof. Nahum Frage for providing the FCT facility at the BGU. R. Marder acknowledges the support of the fellowship from the Women in Science program of the Israel Ministry of Science and Technology.

\section{References}

1. Garay JE, Glade SC, Anselmi-Tamburini U, Asoka-Kumar P, Munir ZA (2004) Appl Phys Lett 85:573

2. Olevsky EA, Froyen L (2009) J Am Ceram Soc 92:S122

3. Chaim R (2013) J Mater Sci 48:502. doi:10.1007/s10853-0126764-9 
4. Holland TR, Anselmi-Tamburini U, Quach DV, Tran TB, Mukherjee AK (2012) J Eur Ceram Soc 32:3659

5. Chaim R, Marder R, Estournés C, Shen Z (2012) Adv Appl Ceram 111:280

6. Conrad H (2002) Mat Sci Eng A322:100

7. Gilman JJ, Johnston WG (1960) J Appl Phys 31:687

8. Johnston WG (1961) J Appl Phys 33:2050

9. Fotedar HL, Stoebe TG (1968) Scripta Metall 2:443

10. Verrall RA, Fields RJ, Ashby MF (1977) J Am Ceram Soc 60:211

11. Marder R, Chaim R, Chevallier G, Estournes C (2011) J Eur Ceram Soc 31:1057

12. Reed JS (1995) Principles of ceramics processing. Wiley, New York

13. Cropper DR, Langdon TG (1968) Phil Mag 18:1181

14. German RM (1989) Particle packing characteristics. Metal Powder Industries Federation, Princetown

15. Budworth DW, Pask JJ (1963) J Am Ceram Soc 46:560

16. Gilman JJ (2003) Electronic Basis of the Strength of Materials. University Press, Cambridge

17. Skvortsova NP (1996) Cryst Res Technol 31:373
18. Gilman JJ (1959) Aust J Phys 13:327

19. Scott WD, Pask JA (1963) J Am Ceram Soc 46:284

20. Arzt E, Ashby MF, Easterling KE (1983) Metall Trans A 14A:211

21. Green DJ (1998) An Introduction to the mechanical properties of ceramics. University Press, Cambridge

22. Helle AS, Easterling KE, Ashby MF (1985) Acta Metall 33:2163

23. Hoover DB, Washburn J (1962) J Appl Phys 33:11

24. Straffelini G (2005) Powder Metall 48:189

25. Fotedar HL, Stoebe TG (1975) Phys Status Solidi A 31:399

26. Shand EB (1968) In: Hausner HH, Gonser BW (eds) Modern Materials: V.6: Advances in Development and Applications Academic Press. New York, pp, p 247

27. Stoebe TG, Huggins RA (1966) J Mater Sci 1:117. doi:10.1007/ BF00550100

28. Bullard JW, Searcy AW (1997) J Am Ceram Soc 80:2395

29. Gilman JJ (1960) J Appl Phys 31:2208

30. Ives MB, Plewes JT (1965) J Chem Phys 42:293

31. Matzke HJ (1971) J Phys Chem Solids 32:437 